\title{
Knowledge, Attitude and Practice of Health Care Personnel about Medical Waste Management in Selected Family Health Centers in Mansoura, Egypt
}

\author{
Hanan Hamed Mohammed ${ }^{1}$, Rabab Gad Abd El-Kader *1, Adel Al-Wehedy Ibrahim ${ }^{2}$ \\ ${ }^{1}$ Department of Community Health Nursing, College of Nursing, Mansoura University, Egypt \\ ${ }^{2}$ Department of Public Health, College of Medicine, Mansoura University, Egypt
}

Correspondence: Rabab Gad Abd El-Kader; E-mail: dr_rabab3@yahoo.com

Received 19 May 2019;

Accepted 02 June 2019;

Published 13 June 2019

\begin{abstract}
Background: Inadequate management of medical waste is a serious problem in many developing countries due to the risks arising to human health and the environment. The study aim was to assess knowledge, attitude and practice of the health care personnel about the medical waste management in the selected family health centers in Mansoura, Egypt. Design: Cross-sectional study approach was utilized. Cluster random sample was used in selecting the family health centers, the health care personnel working in the selected centers were the participant. Knowledge of health care providers was assessed by structured questionnaire. Observation checklists was used to assess their practice and Likert scale questionnaire to assess their attitude. Results: showed incorrect knowledge and improper practices related to different issues handling wastes of chemicals, pressurized containers and radioactive materials in addition, the duration of storage waste among the health care personnel and more than half $(57.5 \%)$ of them had satisfactory attitude. Conclusion: physician and pharmacists had a good knowledge about waste management while most of them had unsatisfactory practice. Nurses had a satisfactory practice and most of the health care workers had satisfactory attitude towards safe waste management. Recommendations: development of in-service training program in relation to awareness and practices of waste disposal for all health care staff, with continuous monitoring at regular intervals. In addition to written policies or clear guidelines of waste management should be available at the family health centers.
\end{abstract}

Keyword: Medical waste management, knowledge, Practices, Attitude, Health care personnel

\section{Introduction}

Medical Waste Management (MWM) is a process that ensures proper hygiene in the health setting, the safety of health care workers and communities ${ }^{[1]}$. Safe health-care waste management is fundamental to ensure the quality, people-centered care, patient protection, the safety of personnel and the environment. This reduces healthcare-associated infections, increases the credibility and uptake of services, increases the efficiency and lowers the cost of service. The process of waste management includes the main stages, which are very important and interrelated. These include the segregation, collection, storage, processing, transportation, treatment and disposal ${ }^{[2]}$.

Poor management of medical waste exposes health workers, waste handlers and the community to infections, toxic effects and injuries. There is also a potential for the spread of drug-resistant microorganisms in the environment ${ }^{[3]}$.

Health care waste (HCW) is defined as the total waste stream from a health care facility that generated during diagnosis, treatment or immunization of human being ${ }^{[4]}$. Approximately $15 \%$ of the medical waste is hazardous, injurious to humans, and environment and has high potential for diseases transmission when not properly managed while approximately $85 \%$ are non-hazardous ${ }^{[2]}$.

WHO (2006) ${ }^{[5]}$ categorized hazardous waste into nine classifications: infectious waste containing pathogenic microorganisms, such as tissues, dressing from infected wounds ${ }^{[6]}$; Sharps and injurious waste refers to waste from medical and intermediate care facilities comprising needles, syringes and scalpels $^{[7]}$; pharmaceutical waste includes terminated or unused pharmaceutical products and spilled contaminated pharmaceutical products $^{[8]}$; Chemical waste comprises discarded solid, liquid or gaseous chemical, such as waste from diagnostic and experimental work; Genotoxic waste includes certain cytostatic drugs that are often used in cancer therapy ${ }^{[9]}$; Radioactive waste comprising radioactive substances which may be solid, liquid and gases, such as vials, syringes, protective clothing, chemical or biological research ${ }^{[10] \&[11]}$; pathological waste including human tissues, organs, body parts, biopsies; wastes with high content of heavy metals represent a subgroup of hazardous chemical waste and 
usually extremely toxic such as mercury; and finally pressurized containers may be explored if burned or by accident penetrated ${ }^{[12]}$.

Sources of HCW include hospitals, diagnostic centers, research facilities, medical laboratories, private clinics, dental clinics and Primary Health care Centers (PHC ${ }^{[13]}$. A PHC is a medical facility that delivers medical care to outpatients and, on occasion, may participate in large-scale immunization programs. PHCs are generally relatively small and produce limited quantities of wastes. Approximate percentage of waste type per total waste in PHC centers: non-infectious waste $80 \%$, pathological waste and infectious waste $15 \%$, sharps waste $1 \%$, chemical or pharmaceutical waste $3 \%$ and pressurizes cylinders, broken thermometers... less than $1 \%{ }^{[14]}$.

The proper handling and disposal of medical waste is very necessary. There are well-defined rules for working with medical waste on a global scale. Unluckily, loosening and lack of appropriate training and awareness of the implementation of these rules lead to health problems and environmental concerns. Nurses and other healthcare workers should be trained of the risks in order to improve their practices with regard to MWM. Since today's nurses and doctors are requested to perform expanded roles under different conditions, they must be environmentally sensitive in assessing the influence of their practices on the environment and how to make available ways to diminish hazards ${ }^{[15]}$.

In a medical waste management study conducted in China, primary care centers had a number of problems, such as lack of equipment, poor waste separation, unhygienic storage sites, inadequate protective measures and risky on-site disposal ${ }^{[16]}$. A major benefit of this study is to help us identify the gaps between the current KAP among health workers involved in waste management and the future desirable condition that needs to be achieved.

For the reason that large number of vaccinations to children against communicable diseases carried out in the Primary Health Centers, a great quantity of needles and syringes are used so it is important to assess Knowledge, Attitude and Practice (KAP) of the health care personnel in the family health centers ${ }^{[13]}$. In Egypt there is a lack of site-specific data on PHCs about the composition and production rates of MSW based on actual measurements rather than assessments. Most of the studies were carried out in hospitals. Hence there is need to assess the knowledge, practice and attitude on medical waste management among health care personnel in the Family Health centers

\section{Aim of the study}

To evaluate the knowledge, practice and attitude on medical waste management among health care personnel in selected Family Health centers in Mansoura District, Dakhalia Governorate, Egypt.

\section{Research questions}

1. What is the level of knowledge among the health care personnel about medical waste management in the Family Health centers?

2. What are the current practices of the health care personnel on medical waste management in the Family Health centers?

3. What is the level of attitude among the health care personnel about management of medical wastes in the Family Health centers?

\section{Subject \& Methods}

\author{
1. Research design: \\ Cross sectional study design was applied.
}

\section{Study settings:}

Study was accomplished at the family health centers affiliated to Mansoura District, Dakhalia governorate. Mansoura District divided into four parts; North, East, West and South and we selected randomly 2 family health centers from each part using cluster random sample.

\section{Subjects of the study}

Health care personnel who were working in the selected family health centers

\section{Inclusion criteria}

All the health care personnel had worked in the selected centers for over 6 months (i.e. physicians, nurses and support staff) who were agreeable to join in the study.

\section{Sampling}

Convenient sample was used to select the health care personnel at the time of collecting and who were agreeable to join in the study that include (120 personnel)

Tools of data collection

Tools were established after reviewing of the related literatures

Tool (1): self - administered structured questionnaire was utilized to collect the data. It consisted of 2 parts:

Part (I): Demographic characteristics for instance age, educational qualification, years of experience, and received training about waste management.

Part (II): Knowledge of health care providers concerning waste management including concept of medical wastes, categories of waste, hazards, safety precaution from waste hazards, steps of waste management, methods of waste disposal, color coding for wastes container, extent of bag filling up reporting of injuries due to improperly disposed injuries. Scoring of the questionnaire is mark of one for the correct answer, zero for the wrong answer \& do not know. For the knowledge score about waste management: poor $<50 \%$; fair from $50-<65 \%$; good $\geq 65$.

Tool (II): Observation checklist to assess practices including follow universal precaution rules: hand washing, personal protective equipment, medical waste segregation, waste collection process, transportation, occupational safety of staff, recapping used needle. This tool will be applied to the groups dealing with wastes. Scoring of the practice is giving a score two for the step always done, one for sometimes done while not done was marked zero. For the health care worker practice score about waste management: unsatisfactory $<75$ while satisfactory $\geq 75$.

Tool (III): Attitude Likert scale questionnaire of health care providers about waste management with 3 point-scale consisted of positive and negative items. Positive as; waste causes hazardous on environment, safe waste management decrease transmission of diseases while negative as; effort of waste management considers budget load on administration, implement of safe disposal increases work overload and management of medical wastes is the work of the team not related to the health care worker. 
Scoring for the attitude scale is giving a score of two for agree, one for ascertain and zero for disagree for positive attitude while for the negative attitude points, scored of two for disagree, one for ascertain and zero for agree. For the attitude score of health care worker about waste management: unsatisfactory $<75$ while satisfactory $\geq 75$.

\section{$\underline{\text { Tool validity \& reliability }}$}

The validity of the content of the developed tools was tested by presenting the tools to five experts in "Community Health Nursing ". Their suggested configurations were made.

Tools Reliability was evaluated by means of Cronbach's alpha (0.73).

\section{Pilot Study}

A pilot study of $10 \%$ of the sample was conducted. They are randomly selected from the same settings and omitted from the sample being tested in order to check the applicability and relevance of the study tools and to test the clarity of the developed questionnaire. The necessary changes were made.

\section{$\underline{\text { Ethical Consideration }}$}

Formal authorizations have been received from the directors of family health centers.

Written consent was obtained from health care workers. Each person has the right to take away from the survey at any phase and the data considered to be confidential and utilized only for study purposes

\section{Data collection procedures:}

The data were collected of 6 weeks duration from May- June 2017. The researchers distributed the tool to health care personal after explanation of the study aim in the selected centers. Observation of the health care personal practice using observation checklist.

\section{Statistical analysis}

The analysis of the data after encoding and input is made using appropriate software package SPSS (Stands for Statistical Product and Service Solutions) version 20. Data were offered by means of descriptive statistics in the arrangement of frequencies, percentage, mean and standard deviation. A Chi-square was used and the Pvalue was significant at $\leq 0.05$.

Table 1: Distribution of the health care personnel in relation to their demographic characteristics

\begin{tabular}{|l|l|l|}
\hline Items & N (120) & $\%$ \\
\hline
\end{tabular}

\begin{tabular}{|l|l|l|}
\hline Age (years) & \multicolumn{2}{|l|}{} \\
\hline $20-<30$ & 28 & 23.4 \\
\hline $30-<40$ & 67 & 55.8 \\
\hline $\begin{array}{l}40-50 \\
\text { Mean } \pm \mathrm{SD}\end{array}$ & $\begin{array}{l}|l| \\
32.85 \pm 6.32\end{array}$ & 20.8 \\
\hline Qualification & \multicolumn{2}{|l|}{} \\
\hline Nurse & 71 & 59.2 \\
\hline Physician & 10 & 8.3 \\
\hline Lab technician & 9 & 7.5 \\
\hline Pharmacist & 14 & 11.7 \\
\hline Sanitary worker & 16 & 13.3 \\
\hline $\begin{array}{l}\text { Duration of work experience } \\
\text { (years) }\end{array}$ & \multicolumn{2}{|l}{} \\
\hline$<10$ & 33 & 27.5 \\
\hline $10-20$ & 73 & 60.8 \\
\hline $\begin{array}{l}>20 \\
\text { Mean } \pm \text { SD }\end{array}$ & 14 & 11.7 \\
\hline $\begin{array}{l}\text { Existence of plans for waste } \\
\text { disposal }\end{array}$ & 33 & 27.5 \\
\hline $\begin{array}{l}\text { Waste management team in } \\
\text { the center }\end{array}$ & 71 & 59.2 \\
\hline
\end{tabular}

Table (1) illuminates the demographic data of the health care personnel in which their mean age was $32.85 \pm 6.32$ years. More than half $(59.2 \%)$ of them were nurses while $(13.3 \%)$ were worker. With regards to the duration of work experience, about two thirds $(60.8 \%)$ had worked from ten to less than twenty years. More than one-fourth $(27.5 \%)$ had existence of plans for waste disposal while more than half $(59.2 \%)$ had waste management team in the family health centers.

\section{Recevied training on waste disposal}

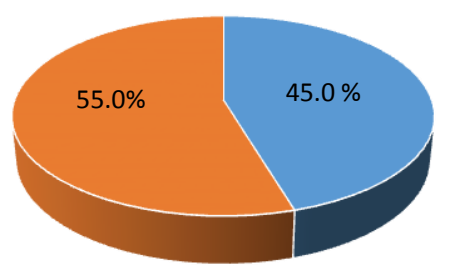

recevied not recevied

Figure (1): Distribution of the health care personnel in relation to their training about waste disposal

Figure (1) Shows that in term of training, less than half (45.0\%) of the health care personnel had received training on waste disposal.

Table (2) Distribution of the health care personnel in relation to their correct knowledge of management of medical waste

\begin{tabular}{|l|c|c|c|c|c|c|}
\hline Items & $\begin{array}{c}\text { Nurses } \\
(\mathrm{n}=71) \\
\mathrm{N}(\%)\end{array}$ & $\begin{array}{c}\text { Physician } \\
(\mathrm{n}=10) \\
\mathrm{N}(\%)\end{array}$ & $\begin{array}{c}\text { Lab } \\
\text { technician } \\
(\mathrm{n}=9) \mathrm{N}(\%)\end{array}$ & $\begin{array}{c}\text { Pharmacist } \\
(\mathrm{n}=14) \\
\mathrm{N}(\%)\end{array}$ & $\begin{array}{c}\text { Sanitary staff } \\
(\mathrm{n}=16) \\
\mathrm{N}(\%)\end{array}$ & $\begin{array}{c}\chi^{2} \\
\text { P- Value }\end{array}$ \\
\hline Def. of medical wastes (2) & $29(40.8)$ & $7(70.0)$ & $7(77.8)$ & $14(100)$ & 0.0 & $40.417<0.001$ \\
\hline Def. of waste management (1) & $50(70.4)$ & $8(80.0)$ & $7(77.8)$ & $13(92.9)$ & $16(100)$ & $17.960<0.001$ \\
\hline Classification of medical waste (3) & $17(23.9)$ & $7(70.0)$ & $8(88.9)$ & 0.0 & 0.0 & $1.405<0.001$ \\
\hline Types of medical waste (7) & $17(23.9)$ & $7(70.0)$ & $8(88.9)$ & $14(100)$ & 0.0 & $52.660<0.001$ \\
\hline Hazards of exposure to infectious waste (4) & $32(45.1)$ & $7(70.0)$ & $9(100)$ & $14(100)$ & $16(100)$ & $33.506<0.001$ \\
\hline Mode of transmission of microorganism (3) & $17(23.9)$ & $7(70.0)$ & $9(100)$ & $14(100)$ & 0.0 & $56.920<0.001$ \\
\hline $\begin{array}{l}\text { Factors contributes exposure to health hazards } \\
\text { (4) }\end{array}$ & $21(29.6)$ & $7(70.0)$ & $8(88.9)$ & $14(100)$ & 0.0 & $46.858<0.001$ \\
\hline Safety precaution from waste hazards (3) & $27(38.0)$ & $7(70.0)$ & $8(88.9)$ & $13(92.9)$ & 0.0 & $36.823<0.001$ \\
\hline Steps of waste management (5) & $17(23.9)$ & $7(70.0)$ & $7(77.8)$ & $14(100)$ & 0.0 & $49.237<0.001$ \\
\hline
\end{tabular}




\begin{tabular}{|l|c|c|c|c|c|c|}
\hline Methods of waste disposal (4) & $20(28.2)$ & $7(70.0)$ & $2(22.2)$ & 0.0 & 0.0 & $21.662<0.001$ \\
\hline Color coding for wastes container (7) & $50(70.4)$ & $8(80.0)$ & $7(77.8)$ & $13(92.9)$ & $16(100)$ & $17.960<0.001$ \\
\hline Extent of bag filling up to75\% (7) & $17(23.9)$ & $7(70.0)$ & $7(77.8)$ & $14(100)$ & 0.0 & $49.237<0.001$ \\
\hline $\begin{array}{l}\text { Reporting of injuries due to improperly disposed } \\
\text { injuries (3) }\end{array}$ & $17(23.9)$ & $7(70.0)$ & $7(77.8)$ & $14(100)$ & 0.0 & $46.858<0.001$ \\
\hline
\end{tabular}

Table (2): illustrates that in relation to the correct knowledge of the health care personnel about waste management, less than half (40.8\%), (45.1\%) of nurses knew definition of medical wastes, hazards of exposure to infectious waste respectively. Less than three-quarter $(70.4 \%)$ of them had correct knowledge about definition of waste management and less than one-quarter (23.9\%) of them had correct knowledge about medical waste classification, types, mode of transmission of microorganism, steps of waste management, extent of bag filling up to $75 \%$, and reporting of injuries due to improperly disposed injuries.

For physician less than three quarter (70\%) of them were knowledgeable about waste management \& most ( $80 \%$ ) of them had correct knowledge about definition of waste management and color coding for wastes container and they did not have knowledge about extent of bag filling up to $75 \%$.
The majority $(88.9 \%)$ of the laboratory technician knew about the waste management, except that they did not know about the filling rate of bags up to $75 \%$ and the color coding of the waste container and only $(22.2 \%)$ had the correct knowledge of waste disposal methods.

All the pharmacists were knowledgeable about overall management of medical wastes except classification of medical waste, methods of waste disposal, extent of bag filling up to75\% and finally color coding for wastes container

All the sanitary staff did not know about management of medical waste except they had correct knowledge about definition of waste management and hazards of exposure to infectious waste.

There is a statistically significant difference among the healthcare personnel with regard to all items of knowledge about waste management $(\mathrm{P}:<0.001)$.

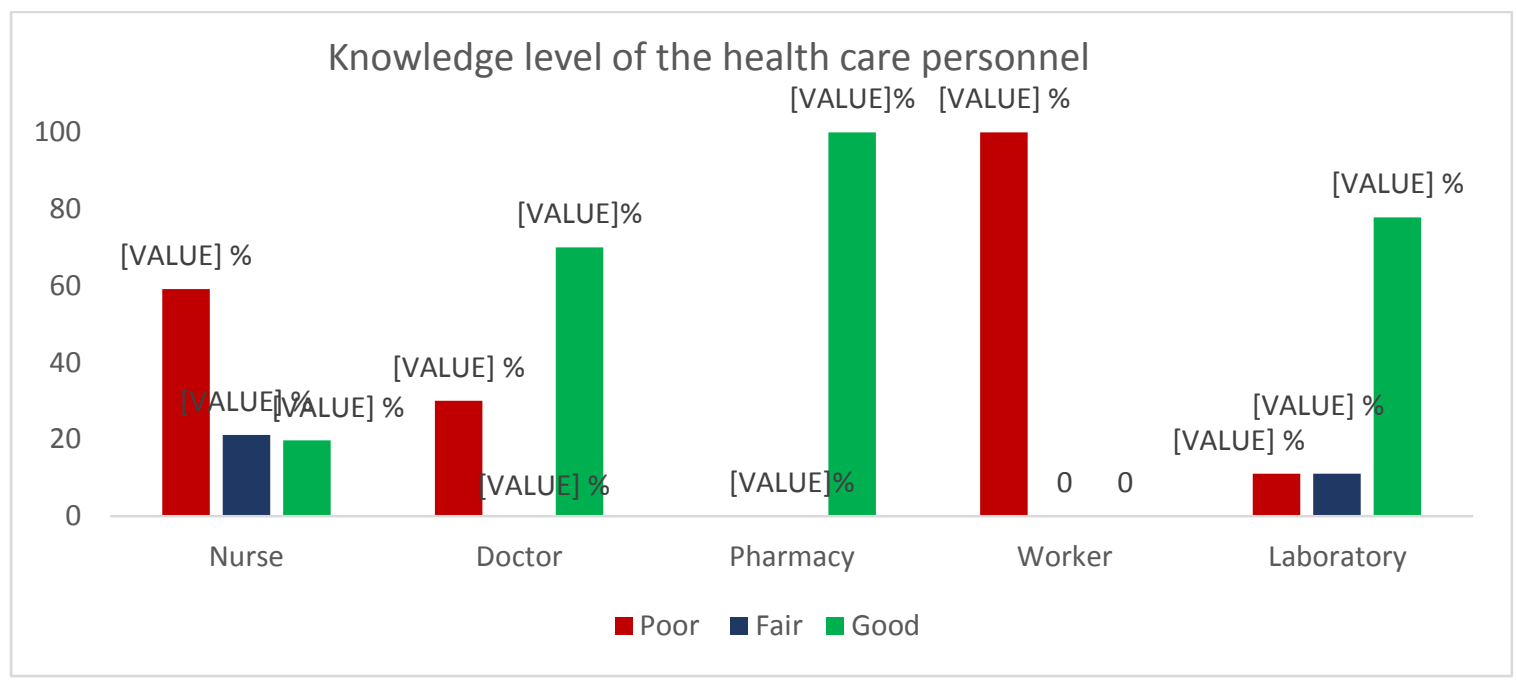

Figure (2): Distribution of the healthcare personnel in relation to their knowledge level about waste management

Figure (2) clarifies that in relation to the knowledge level of health care personnel about waste management; for nurses more than half (59.2\%) had poor knowledge while the minority (19.7\%) had good level. Most (70\%) of the physicians had good knowledge while all the pharmacist had good knowledge about waste management. For the worker poor knowledge level they had while most (77.8\%) of the lab technician had good level about waste management.

Table 3: Distribution of health care personnel according to their correct practice of medical waste management

\begin{tabular}{|c|c|c|c|}
\hline Items correctly performed & $\begin{array}{l}\text { Nurses } \\
(n=71) N(\%)\end{array}$ & $\begin{array}{l}\text { Physician } \\
(\mathbf{n}=10) \mathbf{N}(\%)\end{array}$ & $\begin{array}{l}\text { Sanitary staff } \\
(n=16) N(\%)\end{array}$ \\
\hline $\begin{array}{c}\text { Follow universal precaution rules } \\
-\quad \text { Hand washing }\end{array}$ & $41(57.7)$ & $3(30.0)$ & 0.0 \\
\hline $\begin{array}{ll}- & \text { Personal protective equipment }\end{array}$ & $12(16.9)$ & $4(40.0)$ & 0.0 \\
\hline Medical waste segregation & $58(81.7)$ & --------- & $16(100)$ \\
\hline Waste collection process & $55(77.5)$ & $\begin{array}{ll}------ \\
\end{array}$ & $2(12.5)$ \\
\hline Waste transportation & $44(62.0)$ & ---------- & $1(6.25)$ \\
\hline Occupational safety of staff & $44(62.0)$ & $7(70.0)$ & $2(12.5)$ \\
\hline Final disposal of waste & $44(62.0)$ & $3(30.0)$ & $2(12.5)$ \\
\hline Recapping used needle & $55(77.5)$ & $\begin{array}{c}----- \\
\end{array}$ & --------- \\
\hline Intake of hepatitis B vaccine & $53(74.6)$ & $4(40.0)$ & 0.0 \\
\hline Previous exposure to injury & $6(8.5)$ & $1(10.9)$ & $2(12.5)$ \\
\hline
\end{tabular}

Table (3): Represents the correctly performed practice of the participants about management of medical waste. Regarding follow universal precaution, more than half $(57.7 \%)$ of nurses performed hand washing and only $30 \%$ of physician while sanitary workers didn't perform hand 
washing. More than one-third (40\%) of physician used personal protective measures while only $16.9 \%$ of nurses. All the studied health care workers did not follow waste collection process, waste transportation except more than three quarter ( $77.5 \%)$ and two thirds ( $62.0 \%)$ of nurses respectively. For intake of HB vaccine, around three-quarter (74.6\%) of nurses versus less than half (40\%) while none of the sanitary staff token the vaccine. As regard to previous exposure of injury, the minority of nurses, physician and sanitary staff $(8.5 \%),(10.9 \%),(12.5 \%)$ exposed respectively.

\section{Practice level of Nurses, Doctor and Worker}

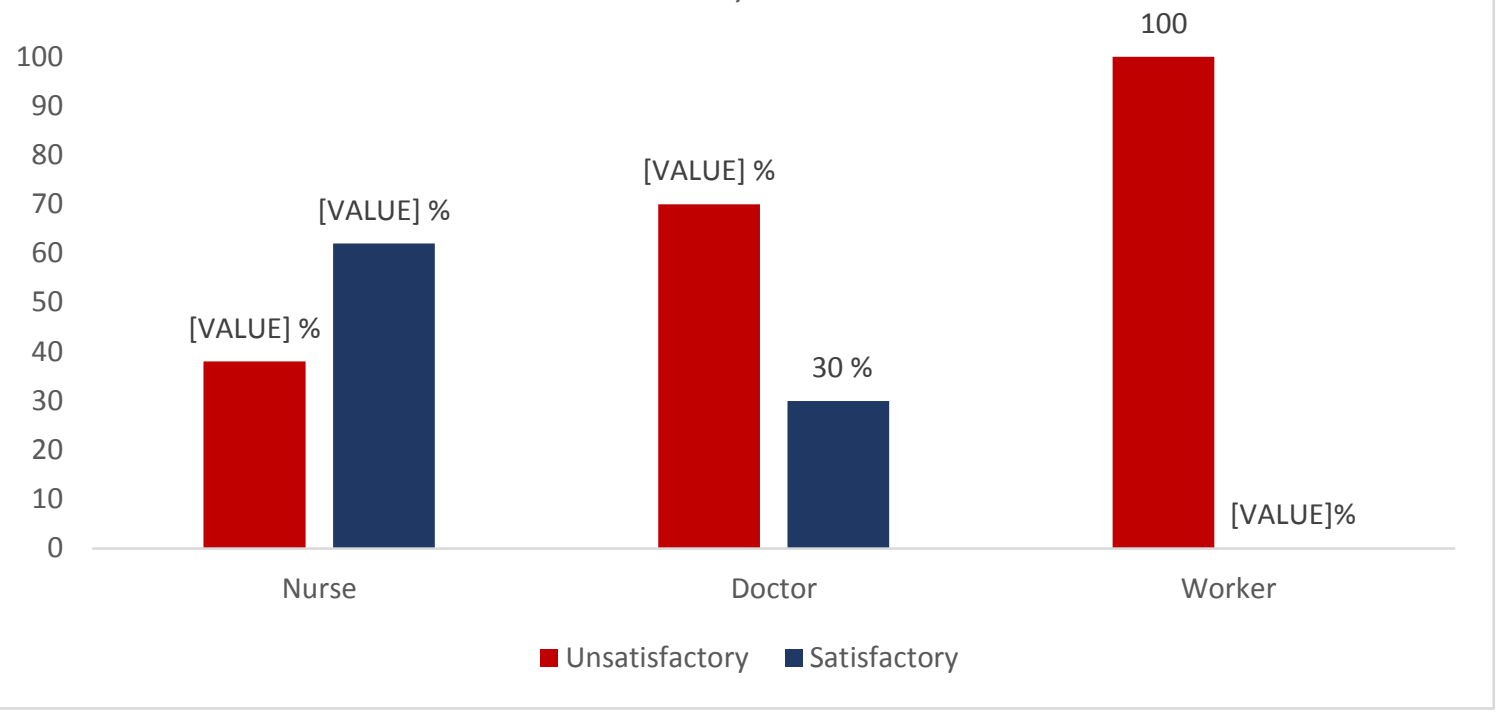

Figure (3): Distribution of nurses, doctors and sanitary workers according to their practice level about medical waste management

Figure (3) illuminates the distribution of nurses, doctors and sanitary workers according to their practice level about waste management; for nurses more than half (62\%) had satisfactory practice while the minority (38\%) had unsatisfactory level. Most (70\%) of the physicians had unsatisfactory level while (30\%) had satisfactory level. All the sanitary workers had unsatisfactory level of practice about waste management.

Table 4: Distribution of health care personnel according to their attitude of waste management

\begin{tabular}{|c|c|c|c|c|c|c|}
\hline \multirow[b]{2}{*}{ Attitude } & \multicolumn{2}{|c|}{ Agree } & \multicolumn{2}{|c|}{ Ascertain } & \multicolumn{2}{|c|}{ Disagree } \\
\hline & $\mathrm{N}$ & $\%$ & $\mathrm{~N}$ & $\%$ & $\mathrm{~N}$ & $\%$ \\
\hline \multicolumn{7}{|l|}{ Positive } \\
\hline Waste causes hazardous on environment & 73 & 60.8 & 14 & 11.7 & 33 & 27.5 \\
\hline Safe waste management decrease transmission of infection & 82 & 68.3 & 8 & 6.7 & 30 & 25.0 \\
\hline Wearing gloves are necessary to prevent hazardous of medical waste & 72 & 60.0 & 22 & 18.3 & 26 & 21.7 \\
\hline Medical wastes segregation is important & 82 & 68.3 & 24 & 20.0 & 14 & 11.7 \\
\hline Application of segregation \&collection waste with safe manner & 76 & 63.3 & 29 & 24.2 & 15 & 12.5 \\
\hline Implementation of safe disposal of waste is important & 98 & 81.7 & 8 & 6.7 & 14 & 11.7 \\
\hline Cooperation with team of waste management is important role in protection & 84 & 70.0 & 28 & 23.3 & 8 & 6.7 \\
\hline It is import to report in case of needle stick & 80 & 66.7 & 29 & 24.2 & 11 & 9.2 \\
\hline Implement safe waste management in health care unit with good manner & 57 & 47.5 & 54 & 45.0 & 9 & 7.5 \\
\hline Always put waste in correct plastic bags & 86 & 71.7 & 27 & 22.5 & 7 & 5.8 \\
\hline As necessary put laws of waste & 36 & 30.0 & 55 & 45.8 & 29 & 24.2 \\
\hline Awareness and training of workers about waste management is necessary & 106 & 88.3 & 14 & 11.7 & $\begin{array}{cc}----- \\
\end{array}$ & ---- \\
\hline \multicolumn{7}{|l|}{ Negative } \\
\hline Effort of waste management consider budget load on administration & 4 & 3.3 & 31 & 25.8 & 85 & 70.8 \\
\hline Implement of safe disposal increases work overload & 29 & 24.2 & 36 & 30.0 & 55 & 45.8 \\
\hline Wearing PPE increases risk of infection & 43 & 35.8 & 16 & 13.3 & 61 & 50.8 \\
\hline Waste disposal is work of team not related to the health care worker & 15 & 12.5 & 7 & 5.8 & 98 & 81.7 \\
\hline
\end{tabular}

Table (4): shows the study group attitude about the medical waste management. For positive attitude, the majority $(81.7 \%, 88.3 \%)$ of the health care workers agreed that cooperation with the team of waste management is important role in protection, awareness and training of workers is necessary. Around two thirds $(60.8 \%, 68.3 \%, 68.3 \%, 63.3 \%, 66.7 \%)$ of the health care workers agreed that wastes cause hazardous on environment, safe waste management decrease transmission of diseases, wearing gloves are necessary to prevent hazardous of medical waste, medical waste isolation is important, application of isolation \&collection waste with safe manner, and it is import to report in case of needle stick respectively.

Regarding the negative attitude, less than three quarter (70.8\%) of the health care worker disagreed that effort of waste management consider budget load on administration, less than half (45\%) of them disagreed that implement of safe disposal increases work overload, and half (50.8\%) 
of them disagreed that wearing PPE increases risk of infection and the majority of the health care personnel disagreed that waste disposal is work of team not related to the health care personnel.

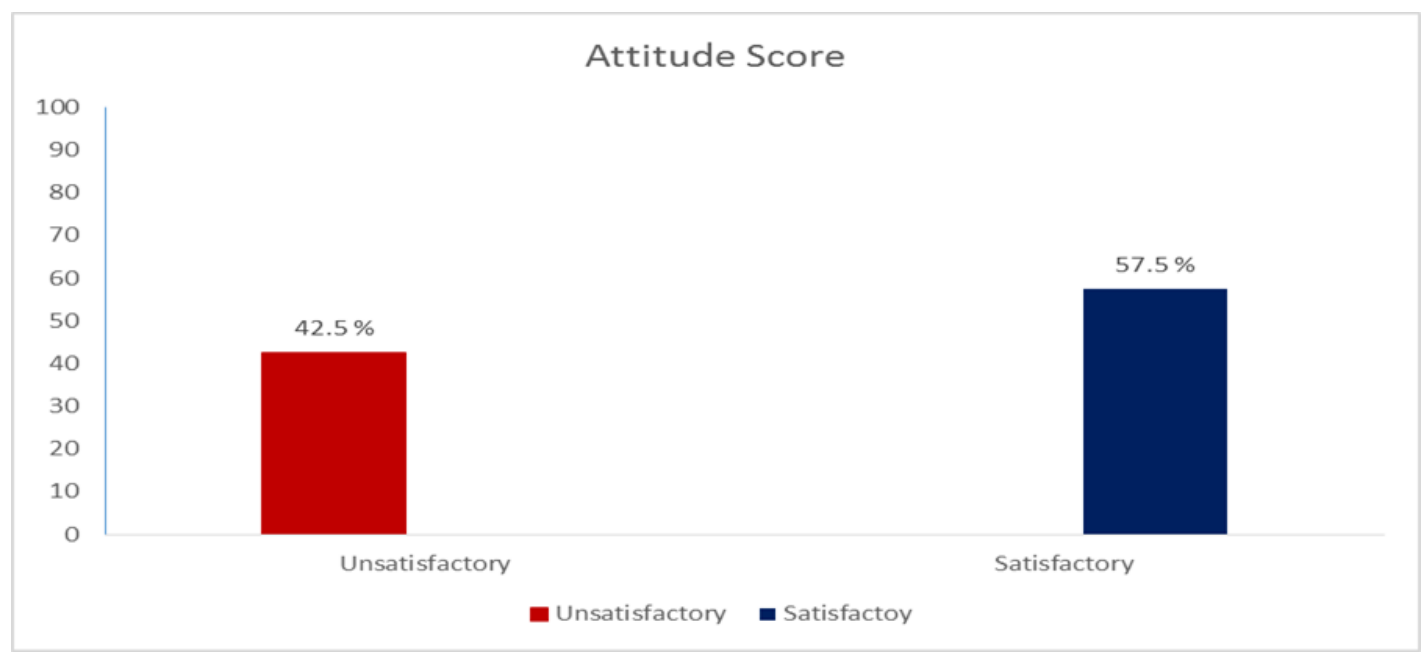

Figure (4): Distribution of the health care personnel in relation to their attitude of waste management

Figure (4) displays that in relation to the attitude level of health care personnel about medical waste management; more than half (57.5\%) of them had satisfactory attitude while more than one-third (42.5\%) had unsatisfactory attitude level about management of the medical wastes.

\section{Discussion}

The key factor for proper management of biomedical wastes is the knowledge, attitude and behaviors of the health care workers in healthcare settings. Team of health care must have an appropriate knowledge level, satisfactory attitude and practices during handling of medical wastes at work that have an impact on the environment and community health ${ }^{[9]}$.

In the current study, it was stated that the family health centers had waste management plan along with team of waste management while less than half of the study group received training on waste disposal. This was in agreement with ${ }^{[17]}$ who found that, $98 \%$ of Istanbul hospitals organized courses for all the health care team about medical waste management. This was in the same line with $^{[18]}$ who found that $67.5 \%$ of nurses had obtained training on waste management in comparison with only $38.2 \%$ of doctors. This was in disagreement with ${ }^{[19]}$ reported that there was a shortage of educational training programs for health care workers pre and postemployment on the topic of medical waste management and in relation to health threats and training was given only to the infection control team.

Regarding correct knowledge of waste management our finding indicated that, pharmacists, physician was significantly higher than nurses and sanitary staff. This was in disagreement with ${ }^{[19]}$ who reported that the health care workers and waste collectors knowledge in the studied ambulatory clinics in Alexandria was not in line with national guidelines of waste management. Acrosssectional study conducted in 8 surgical departments at AlMansoura University Hospitals, Egypt revealed that $36.8 \%$ of physicians, $32.1 \%$ of sanitary workers \& $27.4 \%$ of nurses had good overall knowledge in relation to waste management ${ }^{[20]}$. Good overall knowledge of physician, and pharmacist in the current study due to they had correct knowledge about: definition of waste management, color coding for wastes container, classification, types of medical waste, hazards of exposure to infectious waste, mode of transmission of microorganism, factors contributes exposure to health hazards, Safety precaution, steps \& methods of waste disposal while this deficit of knowledge among nurses and sanitary staff could be due to the deficiency of refresher conferences during employment and inaccessibility of waste management guidelines or handouts to be utilized as a guide. This study also in the same line with the finding of a study in Allahabad city, India, it was stated that doctors, nurses and laboratory technicians had good knowledge than sanitary staff on the topic of management of biomedical waste ${ }^{[21]}$. This was in agreement with a study conducted among hospital staff in a medical college hospital in Bangalore which showed that doctors and nurses had better knowledge than other staff regarding the management of healthcare waste $^{[22]}$. A Nigerian study showed that most health professionals; doctors, nurses and pharmacists had satisfactory knowledge level of collection, minimization and personal threats related to hospital wastes $(93.4 \%, 94.4 \%$ and $97.2 \%$ in that order) ${ }^{[23]}$.

As regards to correctly performed practice of health care team about medical waste management, follow universal precaution, more than half of nurses performed hand washing versus less than one-third of physician while none of the sanitary workers perform hand washing. More than one-third of physician while only less than one-fifth of nurses used personal protective measures. This is may be due to inadequate gloves in most of the studied centers. This agreed with other studies conducted in Bangladesh and India (2013) that found there was a poor practice among health care personnel $^{[14,24,25,26]}$.

The existent study directed that over three-fourth of the nurses recapped the needles after use which is an unsafe practice that expose the individual to the injury. This was in the same line with a study carried out in Puducherry, India stated that just about $50 \%$ of HCPs recap the needle ${ }^{[17]}$. It was moreover in the same line with a survey conducted in Nagara, India according to which the needle recapping practice was $67 \%$ among all the categories of health care personnel $^{[18]}$. An Indian study revealed that recapping practice of the needles was $25 \%{ }^{[27]}$. This resultant differs from a study conducted in Ethiopia, indicating that $(73 \%)$ do not follow the practice of recapping ${ }^{[21]}$. In Lebanon, according to a survey, $67 \%$ of healthcare professionals were attentive that needles should not be abolished after using ${ }^{[22]}$. The practice of recapping in present 
study may be as a result of inadequate awareness and continuance of the old habit, variation in nursing education and inadequate number of needle cutters in the health care facilities (HCFs). This unsafe practice could be managed by providing all HCFs with containers for sharp instruments and enforce the guiding principle for safe disposal.

As regards to practice manner of segregated medical waste, the results of the current study discovered that the types of waste generated from centers such as general, infectious and sharps were disposed in the same line with national guidelines of waste management. These segregated practices were in accordance with the medical waste management practices described in kingdom of Bahrain, and in China where the segregation practices have been implemented as: yellow and red bags for collection of infectious waste; black bags for collection of household waste; while plastic containers for collection of sharps ${ }^{[19,25]}$. These results were supported by WHO recommendations, which reported that using of color-coding system is important to improve the practices of segregation. Cautious segregation of waste into diverse types helps to minimalize the amounts of precarious waste. Segregating hazardous from nonhazardous waste diminishes the risks of infection $^{[2,24]}$. This disagreed with $^{[13]}$ reported that non-sharps wastes were separated in an imperfect manner in some of the PHCs, because of that general waste materials was mixed with a portion of the hazardous MSW. In a study in China carried out to assess health care waste management in the primary health care centers reported that PHCs had several concerns as lack of equipment, poor waste separation, insanitary storage locations, lacking protective measures, and precarious on-site disposal ${ }^{[16]}$.

As regards to healthcare personnel attitude towards management of wastes at primary health care, it was revealed that almost of them agreed that safe waste management decrease transmission of infection, wearing gloves are necessary to prevent hazardous of medical waste, medical wastes segregation is important as well as cooperation with team of waste management is an important in protection. This result was in accordance with ${ }^{[13]}$ reported that health care personal had satisfactory attitude score towards waste disposal. Similarly to India's tertiary health center, doctors (100\%) and nurses $(60 \%)$ had a satisfactory attitude to the requirement for safe collection and final disposal of biomedical wastes ${ }^{[28]}$.

Oppositely, for negative items- almost health care workers disagreed that effort of waste management is considered as budget load on PHCs administration, implementation of safe disposal increases work overload, wearing PPE increases risk of infection and waste disposal is teamwork not related to the health care worker. This disagreed with an Indian study, general practitioners believed that disposing of biomedical wastes is very expensive but cannot be compromised because waste is dangerous and incorrect handling can cause infectious diseases ${ }^{[29]}$. In one more study in a rural tertiary care hospital in India, most of the sanitary staff believed that management of biomedical waste was not considered as a problem at all and is the responsibility of the institution only as well believed that safe waste management is an additional load in the workplace ${ }^{[30]}$.

Satisfactory attitude to safe handling of HCW in the family health centers is a significant resultant in accordance with WHO declaring that concerning safe Management of $\mathrm{HCW}$, human is more significant than technology. Most of the treatment and disposal system that is managed by attentive and well-motivated staff can protect the staff, patients and the community than an expensive or complex system managed by staff who are not aware about hazards, and significance of their role ${ }^{[31]}$.

\section{Conclusion}

As regards to the health care personnel knowledge level, the percentage of correct answers of all items knowledge is significantly higher among physician, pharmacist in comparison to nurses, sanitary worker and technician. As regards to the correctly performed practice of participants about medical waste management, more than half of nurses performed hand washing and only $30 \%$ of physician while sanitary workers didn't perform hand washing. More than one-third of physician used personal protective measures while only $16.9 \%$ of nurses. Most of the nurses correctly perform waste segregation and collection while the majority recap the needle. For the attitude level, most of the participants had satisfactory attitude in the direction of safe waste management as decrease transmission of infection, wearing gloves are necessary to prevent hazardous of medical waste.

\section{Recommendations}

The recommendations of the study are explored:

- Implementation of in-service training program for all health care personnel with regard to knowledge and practices of management of the medical wastes, with regular monitoring at fixed periods.

- Establish waste management team

- Written policies or clear guidelines of waste management should be available at primary health care centers

\section{References}

[1] WHO (2011) Fact sheet: Wastes from Health-care Activities, New Delhi, 2011.

[2] WHO (2017) Safe management of wastes from healthcare activities: A summary WHO/FWC/WSH/17.05 (https://creativecommons.org/licenses/by-ncsa/3.0/igo).

[3] WHO (2015). Health-care waste. Fact sheet no. 253. http://www.who.int/mediacentre/factsheets/fs253/en/ (accessed 19 April 2017).

[4] Maina et al., (2016) Assessment of Level of Knowledge in Medical Waste Management in Selected Hospitals in Kenya. Applied Microbiology: Open Access, 2:4. DOI: 10.4172/2471-9315.1000124.

[5] WHO, (2006). Waste Management during Routine Medical Activities, Health Care Waste. Available at http://www.wastemanagement/WHO/health-carewaste.

[6] Taghipour, H. and M. Mosaferi, (2009). The Challenge of Medical Waste Management: A Case Study in Northwest of Iran- Tabriz. Waste Manage Res. May26 (E pub ahead of print). Available at; http://www.Pubmed.com.

[7] Athy, L.R., (2009). Biomedical waste Management Regulatory Compliance and Management of BMW Facilities. Available at http://www.basel.int/natreporting/cfs/.doc

[8] Longe, E.O. and A. Williams, 2006. A preliminary Study of Medical Waste Management in Lagos Metropolis. Nigeria. Iran. J. Environ. Health. Sci. Eng., 3(2): 133139.

[9] Roy, V., P. Gupta and M.C. Joshi, 2005. Practical Guidelines for Disposing Cytotoxic Waste. Waste 
Management.

Available

at

http://www.expresspharmaonline.com/20050526.

[10] The department of human services. The Blue Book Guidelines for the Control of Infectious Diseases. 2005.

Available

at http://www.health.Vic.gov.au/ideas/bluebook.

[11] WHO, (2010) Preparation of National Heath Care Waste Management Plans in sub-Saharan Countries. Available at

Uhttp://www.who.int/water_sanitation_health/medicalwa ste/guidmanual/enU.

[12] Alagoz, B.A. and G. Kocasoy, 2007. Treatment and Disposal Alternatives for Health Care Wasies in Developing Countries- A case Study in Istanbul, Turkey. Waste Manag. Res., 25: 83-89.

[13] Al-Khatib. I.A. (2013) Problems of management of medical solid waste at primary health care centers in the Palestinian Territory and their remedial measures. Eastern Mediterranean Health Journal (EMHJ). Vol. 19. Supplement 3. 152-158.

[14] WHO, (2005) Management of Solid Health-Care Waste at Primary Health-Care Centers. A Decision-Making Guide. Immunization, Vaccines and Biologicals (IVB). Protection of the Human Environment. Water, Sanitation and Health (WSH). World Health Organization. Geneva, 2005.

[15] El-Sayed. S.H, Zakaria. A .M and Gheith. N. AR (2012) Intervention Program for Nurses about Health Care Waste Management. Research Journal of Medicine and Medical Sciences, 7(1): 25-37, 2012. ISSN 1816-272X

[16] Ruoyan $G$ et al. Investigation of health care waste management in Binzhou District, China. Waste Management (New York, N.Y.), 2010, 30:246-250.

[17] Abdulla, F., Abu Qdais, H., \& Rabi, A. (2008). Site investigation on medical waste management practices in northern Jordan. Waste Management, 28(2), 450-458. doi:10.1016/j.wasman.2007.02.035.

[18] Hakim. S. A. Mohsen. A. and Bakr. I. (2014).Knowledge, attitudes and practices of health-care personnel towards waste disposal management at Ain Shams University Hospitals, Cairo. Eastern Mediterranean Health Journal (EMHJ).Vol. 20 No. 5.

[19] Mohamed S.S. Abd El-Razek. M.M. \& Zaki. I.H. (2016). Medical Waste Management Situation at Alexandria Ambulatory Clinics. IOSR Journal of Nursing and Health Science (IOSR-JNHS) e-ISSN: 2320-1959.p- ISSN: 2320-1940 Volume 5, Issue 5 Ver. V (Sep. - Oct. 2016), PP 01-09 www.iosrjournals.org.
[20] Mostafa GM, Shazly MM, Sherief WI. Development of a waste management protocol based on assessment of knowledge and practice of healthcare personnel in surgical departments. Waste Management, 2009, 29:430439.

[21] Mathur V et al. Knowledge, attitude and practices about BMW management among health care personnel: a cross-sectional study. Indian Journal of Community Medicine, 2011, 36:143-145.

[22] Madhukumar S, Ramesh G. Study about awareness and practices about health care waste management among hospital staff in a medical college hospital, Bangalore. Iranian Journal of Basic Medical Sciences, 2012, 3:7-11.

[23] Samuel SO, Kayode OO, Musa OI. Awareness, practice of safety measures and the handling of medical wastes at a tertiary hospital in Nigeria. Nigerian Postgraduate Medical Journal, 2010, 17:297-300.

[24] Sawalem, M., Selic, E., \&Herbell, J. . (2009). Hospital waste management in Libya: A case study. Waste Management, $\quad 29(4), \quad 1370-\quad 1375$. doi:10.1016/j.wasman.2008.08.028.

[25] Bendjoudi, Z., Taleb, F., Abdelmalek, F., \&Addou, A. (2009). Healthcare waste management in Algeria and Mostaganem department. Waste Management, 29(4), 1383-1387. doi:10.1016/j.wasman.2008.10.008

[26] Diaz, L. F., Savage, G. M., \&Eggerth, L. L. (2005). Alternatives for the treatment and disposal of healthcare wastes in developing countries. Waste Management, 25(6), 626-637. doi:10.1016/j.wasman.2005.01.005.

[27] Kontogianni, S., Xirogiannopoulou, A., \&Karagiannidis, A. (2008). Investigating solid waste production and associated management

[28] Sachan R, Patel ML, Nischal A. Assessment of the knowledge, attitude and practices regarding biomedical waste management amongst the medical and paramedical staff in tertiary health care center. International Journal of Scientific and Research Publications, 2012, 2(7):1-6.

[29] Bhasker B, Nidugala H, Avadhani R. Biomedical waste management - knowledge and practices among health care providers in Mangalore. Nitte University Journal of Health Science, 2012, 2:35-36.

[30] Radha R. Assessment of existing knowledge, attitude and practices regarding biomedical waste management among the health care workers in a tertiary care rural hospital. International Journal of Health Services and Research, 2012, 2:14-19.

[31] WHO (2010). Safe management of wastes from healthcare activities, Op. cit. 